\title{
SCIGN-New Southern California GPS Network Advances the Study of Earthquakes
}

\begin{abstract}
outhern California is a giant jigsaw puzzle, and scientists are now using GPS satellites to track the pieces. These puzzle pieces are continuously moving, slowly straining the faults in between. That strain is then eventually released in earthquakes. The innovative Southern California Integrated GPS Network (SCIGN) tracks the motions of these pieces over most of southern California with unprecedented precision. This new network greatly improves the ability to assess seismic hazards and quickly measure the larger displacements that occur during and immediately after earthquakes.
\end{abstract}

The Southern California Integrated GPS Network (SCIGN) is a network of 250 continuously operating Global Positioning System (GPS) stations completed in July 2001. GPS is a constellation of navigation satellites that are used in conjunction with ground or airborne receivers to provide precise altitudes and horizontal positions. Earthquake researchers have developed ways to use GPS to precisely measure the deformation of the Earth's crust, which can occur as slip on faults, as folding of rock layers, or as the slow elastic distortion of the ground. The link between the motions of the plates that make up the Earth's crust and the resulting earthquakes is now being directly observed in southern California.

Using SCIGN, scientists measure the inexorable and mostly steady deformations of the Earth's crust and map the buildup of the resulting strain. These ground motions are small, a few inches per year or less. Seismic networks cannot detect this slow strain accumulation, because it occurs without ground shaking. When a significant earthquake occurs, SCIGN measures the sudden release of the strain, and for larger earthquakes, SCIGN measures the deformation that occurs during the next few months.

Scientists of organizations participating in the Southern California Earthquake Center (SCEC) designed and manage SCIGN. The U.S. Geological Survey (USGS), NASA's Jet Propulsion Laboratory (JPL), and the Scripps
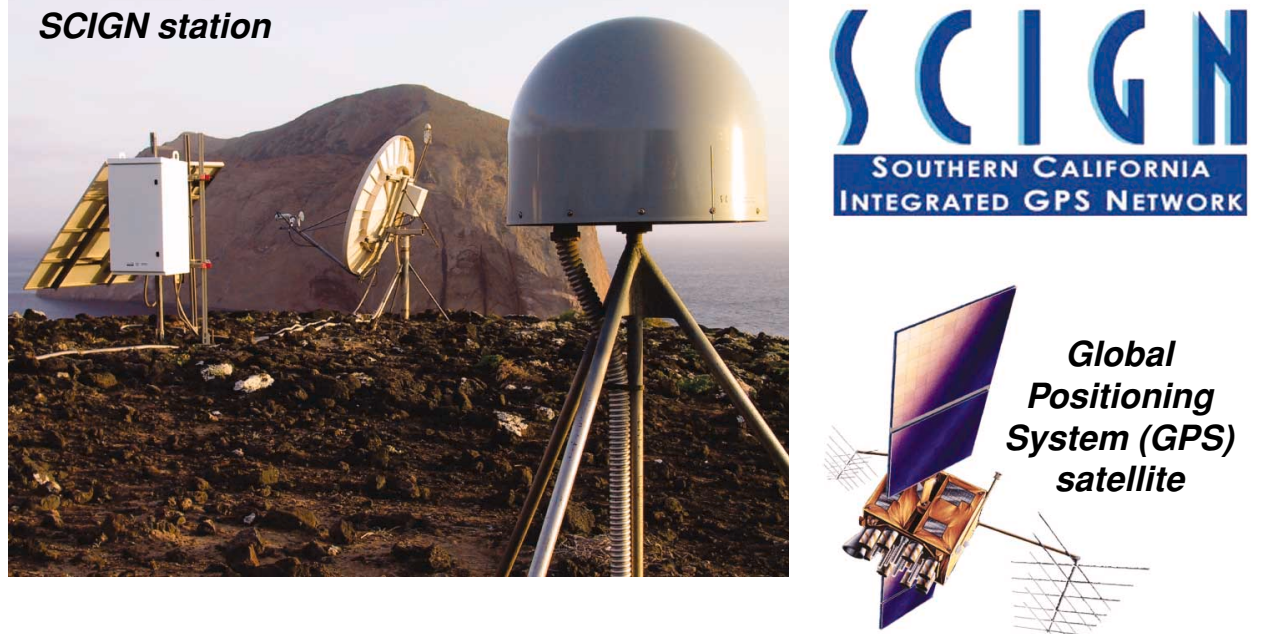

\section{SCIGN stations receive radio signals from GPS satellites overhead...}

Major objectives of SCIGN:

- To measure crustal movements throughout southern California for better estimating earthquake potential.

- To identify active blind thrust faults and test models of compressional tectonics in the Los Angeles region.

- To measure local variations in strain rate that might reveal the mechanical properties of earthquake faults.

- In the event of an earthquake, to measure permanent crustal deformation not detectable by seismographs, as well as the response of major faults to the regional change in strain. ....and scientists use the data to observe motion on active faults, and to better assess earthquake hazards.

Compression along the San Andreas Fault's "Big Bend" squeezes the Los Angeles region, pushing up the San Gabriel Mountains. SCIGN data record this slow strain buildup. 


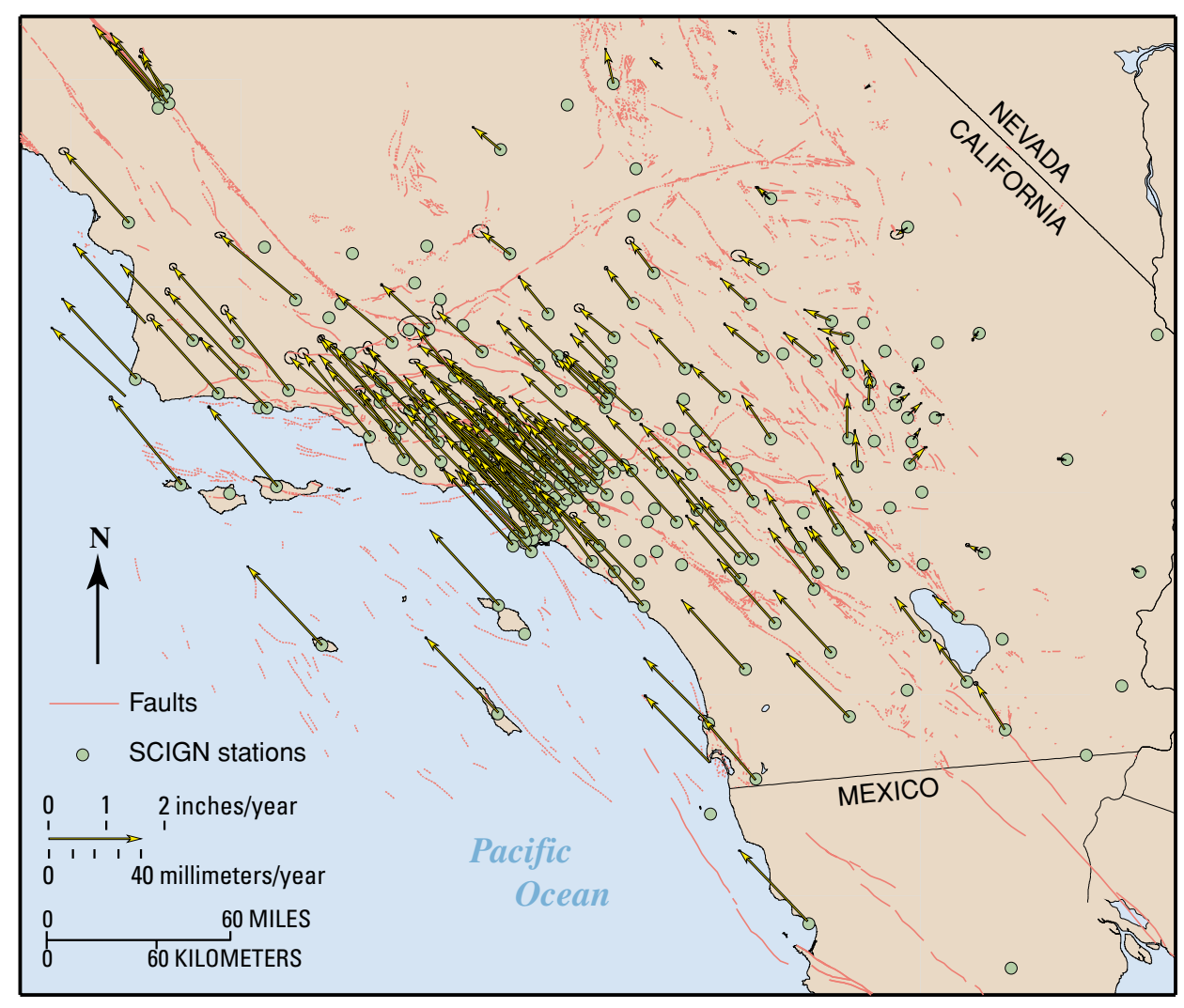

Institution of Oceanography at the University of California at San Diego are the main participants in SCIGN. In addition, land surveyors founded the California Spatial Reference Center to help their community use GPS data and to build on and sustain SCIGN and other networks. Funding for SCIGN is provided by the W.M. Keck Foundation, the National Science Foundation (NSF), NASA, and the USGS.

\section{SCIGN Helps Answer Crucial Questions}

Many unanswered scientific questions remain about the nature of active faults beneath southern California. SCIGN data are already showing new details about north-south compression across the Los Angeles Basin. Several possible models have been proposed to explain this compression. As a longer record of SCIGN data is compiled, scientists will be better able to resolve these debates. The answers are crucial for the assessment of earthquake hazards.

Scientists used SCIGN to study the deformation during and after the 1999 magnitude 7.1 Hector Mine earthquake in the Mojave Desert northeast of Los Angeles. New SCIGN stations were immediately installed near the epicenter, and they have been invaluable in monitoring the post-earthquake deformation.

\section{Major funding for SCIGN provided by:}

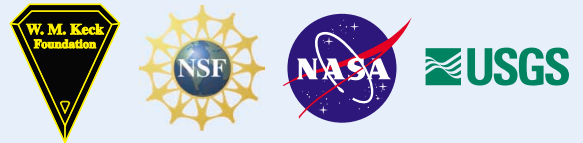

Such studies are helping scientists to better understand earthquakes.

SCIGN is also being used to monitor large engineered structures. For example, in cooperation with Los Angeles County, SCIGN continuously measures small motions of Pacoima Dam in the San Fernando Valley.

\section{SCIGN Data Assist Many Users}

SCIGN data are freely available to anyone over the Internet (http://www.scign.org/). Each month, people retrieve more than 50,000 SCIGN data files, and this number continues to increase. The majority of the hundreds of SCIGN data users are scientists working in universities and government agencies around the world.

The other major use of SCIGN data is by land surveyors and engineers in southern California. In this actively deforming region, SCIGN stations are increasingly being used instead of old survey markers. SCIGN is providing essential infrastructure for positioning everything from property boundaries to cargo ships entering harbors.

SCIGN is an effective partnership between scientists, surveyors, and engineers. This activity is advancing high-precision GPS technology and is applying it to improve assessments of earthquake hazards in southern California. In coming decades, large earthquakes will certainly strike this region, where millions of people are at risk. SCIGN data will help in reducing the loss of life and property by providing a better understanding of the earthquake hazards.
There are 250 SCIGN stations (green dots) in southern California. Stations are concentrated in the Los Angeles region, because this densely populated area has a large seismic hazard and little was known about deformation in the region before SCIGN. Motion of the Pacific Plate past the North American Plate in southern California is shearing the entire region and causing the Los Angeles Basin to be compressed in a north-south direction. SCIGN data provide a new and more precise look at this motion. The slow movement of each SCIGN station, relative to the interior of the North American Plate, is shown by the arrows on the map. Scientists use these motions to calculate strain accumulation in the Earth's crust in southern California. Strain builds up slowly over time and is released suddenly during earthquakes. The accumulated strain is directly related to earthquake potential, and measurement of it contributes to hazard assessments that help people to prepare for the earthquakes that are certain to occur in the future.

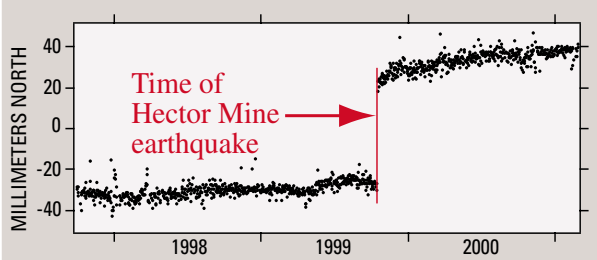

Scientists keep daily track of the horizontal and vertical position of each SCIGN station. Plate motions usually cause the positions of the stations to change slowly and steadily over time, but the positions may change abruptly during earthquakes. This plot shows changes in the north-south position of a SCIGN station near Palm Springs before and after the 1999 magnitude 7.1 Hector Mine earthquake. The station moved 50 millimeters to the north during the earthquake.

\section{For More Information:}

Southern California Earthquake Center (SCEC)

University of Southern California

Los Angeles, CA 90089-0742

(213) 740-5843

scecinfo@usc.edu

http://www.scign.org/

SCEC Outreach: Mark Benthien

USGS Pasadena Outreach: Lisa Wald

SCIGN Executive Committee: Ken Hudnut, Yehuda Bock, Frank Webb, Bill Young

SCIGN Network Coordinator: John Galetzka

SCIGN Network Administrator: John McRaney

\section{COOPERATING ORGANIZATIONS}

\section{W.M. Keck Foundation}

National Aeronautics and Space Administration

National Science Foundation

U.S. Geological Survey

Southern California Earthquake Center

University of Southern California

Jet Propulsion Laboratory

Scripps Institution of Oceanography, University of

California at San Diego

California Department of Transportation

California Spatial Reference Center

Los Angeles County

Centro de Investigación Cientifica y de Educación

Superior de Ensenada

This Fact Sheet and any updates to it are available online at

http://geopubs.wr.usgs.gov/fact-sheet/fs069-01/

Written by Ken Hudnut and Nancy King 